\title{
Impression management and achievement motivation: investigating substantive links
}

Article

Accepted Version

Elliot, A., J., Aldhobaiban, N., Murayama, K., Kobeisy, A., Gocłowska, M. A. and Khyat, A. (2018) Impression management and achievement motivation: investigating substantive links. International Journal of Psychology, 53 (1). pp. 16-22. ISSN 0020-7594 doi:

https://doi.org/10.1002/ijop.12252 Available at https://centaur.reading.ac.uk/65728/

It is advisable to refer to the publisher's version if you intend to cite from the work. See Guidance on citing.

To link to this article DOI: http://dx.doi.org/10.1002/ijop.12252

Publisher: Wiley

All outputs in CentAUR are protected by Intellectual Property Rights law, including copyright law. Copyright and IPR is retained by the creators or other copyright holders. Terms and conditions for use of this material are defined in the End User Agreement.

\section{www.reading.ac.uk/centaur}

\section{CentAUR}


Central Archive at the University of Reading

Reading's research outputs online 
Impression management and achievement motivation: Investigating substantive links

\author{
Andrew J. Elliot ${ }^{1,2}$, Nawal Aldhobaiban ${ }^{2}$, Kou Murayama ${ }^{3}$, Ahmed Kobeisy $^{2}$, \\ Małgorzata A. Gocłowska ${ }^{1,4}$, \& Aber Khyat $^{2}$
}

Short Title: Impression Management

Word count: 4731

\footnotetext{
${ }^{1}$ University of Rochester

${ }^{2}$ King Abdulaziz University

${ }^{3}$ University of Reading

${ }^{4}$ University of Amsterdam
} 


\begin{abstract}
In the present research we investigate impression management (IM) as a substantive personality variable by linking it to differentiated achievement motivation constructs, namely achievement motives (workmastery, competitiveness, fear of failure) and achievement goals (mastery-approach, mastery-avoidance, performance-approach, performance-avoidance). Study 1 revealed that IM was a positive predictor of workmastery and a negative predictor of competitiveness (with and without self-deceptive enhancement (SDE) controlled). Studies $2 \mathrm{a}$ and $2 \mathrm{~b}$ revealed that IM was a positive predictor of mastery-approach goals and mastery-avoidance goals (without and, in Study $2 b$, with SDE controlled). These findings highlight the value of conceptualizing and utilizing IM as a personality variable in its own right, and shed light on the nature of the achievement motive and achievement goal constructs.
\end{abstract}

Keywords: impression management, achievement motivation, motives, goals, self-deceptive enhancement 
Personality researchers have long used measures of social desirability to assess and control for participants' self-report biases. Over the past two decades, the most popular of these measures has been the impression management (IM) scale of the Balanced Inventory of Desirable Responding (BIDR; Paulhus, 1991), which was designed to assess excessively favorable self-reports motivated by a desire to impress others. Although this IM measure is commonly portrayed and utilized as an indicator of response bias alone, it has also been construed as capturing substantive, as well as extraneous, variation (Paulhus, 2002; Uziel, 2010). As such, it is important to investigate how IM scores are related to variation in other indicators of personality and psychological functioning. The investigation of such relations promises to not only yield a broader understanding of IM, but also a richer understanding of the other constructs to which IM is linked.

A number of researchers and theorists over the years have described IM, and social desirability more generally, in substantive terms as well as response bias terms. Some have conceptualized IM as approval motivation (Crowne \& Marlowe, 1964) and have emphasized the more defensive, self-protective aspects of this motivational tendency (see Crowne, 1979; Strickland, 1977). However, others have conceptualized IM in a more positive, adaptive manner, describing it as regulation aimed at maintaining social harmony (Schlenker \& Britt, 2001), the ability to override one's own interests for the betterment of others (Tangney, Baumeister, and Boone, 2004), and interpersonal sensitivity (Holden \& Fekken, 1989). Uziel (2010; 2014) has persuasively argued that the available data on IM measures support the latter more than the former characterization. He posited that the substantive component of IM represents self-control aimed at social adaptation. From this perspective, IM scores reflect accurate reports of respondents' self-regulation, specifically their actual behavior based on what they think is right 
and good in the context of their relations with others and society in general.

The extant research on IM and indicators of personality and psychological functioning has found links between IM and a variety of different dispositions (e.g, Big Five traits), behaviors (e.g., interpersonal behavior), processes (e.g., affective experience), and outcomes (e.g., job performance) from diverse areas. Achievement motivation is one such area that has received attention. Links between IM and two different achievement motivation constructs have been examined: ${ }^{1}$ need for achievement (an achievement motive; Uziel, 2014, Study 3; Moorman \& Podsakoff, 1992, Study 2) and achievement striving (a facet of trait conscientiousness; Pauls, Wacker, \& Crost, 2005). In both instances, null relations were observed. Based on these data, one might conclude that IM is unrelated to achievement motivation. It would be premature to draw this conclusion, however, because achievement motivation is conceptualized in other ways, besides unidimensional motives and traits.

Indeed, three conceptual distinctions foundational to the achievement motivation literature may be considered with regard to the IM-achievement motivation relation. First, achievement motivation may be differentiated in terms of level of analysis -- motivational dispositions versus situation-specific goals (Dweck \& Elliott, 1983). Second, achievement motivation may be differentiated in terms of how competence is defined -- a self-based standard versus an other-based standard. Thus, achievement motives can be represented as workmastery (desiring to do one's best) or competiveness (desiring to beat others; Spence \& Helmreich, 1983), and achievement goals may be represented as mastery goals (focused on improvement) or performance goals (focused on normative rank; Ames, 1992). Third, achievement motivation may be differentiated in terms of how competence is valenced -- approaching success versus avoiding failure. Thus, achievement motives not only encompass workmastery and 
competitiveness (approach motives), but also fear of failure (an avoidance motive representing the desire to avoid the shame of failure; Atkinson, 1957). Achievement goals not only encompass mastery-approach goals (trying to do better than before) and performance-approach goals (trying to do better than others), but also mastery-avoidance goals (trying to avoid doing worse than before) and performance-avoidance goals (trying to avoid doing worse than others; Elliot, 1999).

In the present research, we examined links between IM and each of the aforementioned, differentiated achievement motivation constructs, working from the assumption that IM is a substantive personality variable reflecting positive, proactive interpersonal regulation and social adjustment. From this standpoint, university students (the focus herein) high in IM should engage in achievement settings in a way that adapts to socially endorsed educational values and attends to interpersonal connections with classmates. Workmastery and mastery-approach goals are clearly encouraged at school and are conducive to social connection (Darnon, Dompnier, Delmas, Pulfrey, \& Butera, 2009; Dompnier, Darnon, \& Butera, 2009), whereas fear of failure tends to be discouraged at school and may interfere with secure attachments to others (Elliot \& Reis, 2003; Elliot \& Thrash, 2004). Accordingly, IM is likely to be positively related to workmastery and mastery-approach goals, and negatively related to fear of failure. The picture for competitiveness and performance-approach goals is less clear, as they are often both discouraged (explicitly) and encouraged (implicitly) at school (Dompnier et al., 2009), and can clearly interfere with peer relations (Deutsch, 1949; Nicholls, 1989). The picture for masteryavoidance and performance-avoidance goals is likewise mixed, as avoidance goals tend to be discouraged at school, yet they can positively communicate humility or modesty to peers (Darnon et al., 2009). Thus, it is difficult to anticipate, a priori, how IM will be linked to these variables. 
The self-deceptive enhancement (SDE) scale is a second component of the BIDR and it is used to assess exaggerated positive beliefs about oneself (Paulhus, 1991). Conceptually, SDE is viewed as a nonconsciously driven tendency to portray oneself in an overly positive manner (Paulhus, 1991). In the present research, our primary focus is on IM, because it has received the most conceptual and empirical attention, especially recently (Uziel, 2010; 2014), as a substantive variable. However, we included SDE in several studies as well, both for comparison sake (i.e., comparing correlates of IM with those of SDE) and for use as a control variable (i.e., examining IM associations with SDE variance held constant; see Uziel, 2014, for a rationale for this use of SDE). We had no a priori predictions regarding how SDE would fare in either of these uses.

\section{Study 1}

In Study 1 we investigated relations between IM and differentiated achievement motives, namely workmastery, competitiveness, and fear of failure. We also examined SDE-achievement motive relations and the IM-achievement motive relations with SDE controlled.

\section{Method}

\section{Participants and Procedure}

229 undergraduates $(60.3 \%$ female, $0.4 \%$ unspecified) in a psychology class in the U.S. participated for extra course credit. The mean age of participants was 19.8 years old (range $=17$ 55), and participant ethnicity was: $68.1 \%$ Caucasian, 5.7\% African-American, $12.2 \%$ Asian, 2.6\% Hispanic, $11.3 \%$ “Other/unspecified”. Participants completed the IM and SDE questionnaires in a large group session during the first week of the semester, and completed achievement motivation measures in a take-home packet during the next five day period.

This and the following studies were a part of larger projects on motivation and personality; portions of the data from some of these larger projects have been published in prior 
work (for Study 1: see Elliot \& Thrash, 2002, Study 6; Thrash \& Elliot, 2003, Study 1b; for Study 2b: see Weidman, Tracy, \& Elliot, in press, Study 4), but none of the variables used herein have been used previously. In all studies, no manipulations and no data exclusions were used, and all variables that were analyzed for this research are reported. Sample sizes were based on the maximum number of participants that could be recruited during the predetermined period of data collection.

\section{Measures}

Achievement motives. Spence and Helmreich's (1983) Work and Family Orientation Scale was used to assess the two approach-oriented achievement motives, workmastery (14 items: e.g., "There is satisfaction in a job well done"; $\alpha=.77$ ) and competitiveness (5 items: e.g., "I feel that winning is important in work and games"; $\alpha=.79)$. Participants responded on a 1 (Strongly Disagree) to 5 (Strongly Agree) scale.

The short form of Herman's fear of failure measure (Thrash \& Elliot, 2003) was used to assess the avoidance-oriented achievement motive, fear of failure (9 items: e.g., "I often avoid a task because I am afraid that I will make mistakes"; $\alpha=.77)$. Participants responded on a 1 (Strongly Disagree) to 5 (Strongly Agree) scale.

IM and SDE. Paulhus' (1991) Balanced Inventory of Desirable Responding (BIDR) was used to assess IM (20 items: e.g., "I never swear"; $\alpha=.80)$ and SDE (20 items: e.g., "I always know why I like things; $\alpha=.67$ ). Participants responded on a 1 (Not True) to 5 (Very True) scale.

\section{Results and Discussion}

We computed Pearson Product Moment Correlations to examine the relations between IM, SDE, and each of the achievement motive variables (see Table 1). The correlations revealed a statistically significant positive relation between IM and workmastery $(r=.29, p<.001)$, a 
statistically significant negative relation between IM and competitiveness $(r=-.23, p<.001)$, and a marginally significant negative relation between IM and fear of failure $(r=-.12, p=.083)$. The correlations also revealed a statistically significant positive relation between SDE and workmastery $(r=.30, p<.001)$ and a statistically significant negative relation between SDE and fear of failure $(r=-.49, p<.001)$.

Table 1

Impression management and achievement motives (Study 1).

\begin{tabular}{llllll}
\hline & $M(S D)$ & & Correlation $(\mathrm{r})$ & Regression $(\beta)$ \\
\hline Motives & & IM & SDE & IM & SDE \\
\hline Workmastery & $3.64(0.45)$ & $.29 * *$ & $.30 * *$ & $22 * *$ & $.24 * *$ \\
Competitiveness & $3.18(0.84)$ & & & & \\
Fear of failure & $2.59(0.64)$ & $-.23^{* *}$ & -.05 & $-.23 * *$ & .01 \\
\hline
\end{tabular}

Note $:{ }^{+} p<.10 * p<.05, * * p<.01 . \mathrm{IM}=$ Impression Management $(M=3.62, S D=0.87) ; \mathrm{SDE}=$ Self-Deceptive Enhancement $(M=4.15, S D=0.63)$. Coefficients in the correlation column are $r \mathrm{~s}$; coefficients in the regression column are $\beta \mathrm{s} . N=229$ for SDE and IM assessments, $N=218$ for motive assessments.

We conducted multiple regression analyses to examine IM and SDE as simultaneous predictors of each of the motive variables; this allowed an examination of IM relations with SDE variation controlled. IM was shown to be a statistically significant positive predictor of workmastery $(\beta=.22, p<.001)$, as was $\operatorname{SDE}(\beta=.24, p<.001)$. IM was also a statistically significant negative predictor of competitiveness $(\beta=-.23, p<.001)$, and SDE was also a 
statistically significant negative predictor of fear of failure $(\beta=-.50, p<.001)$.

In sum, IM was shown to be positively related to workmastery and negatively related to competitiveness, both alone and with SDE controlled; IM was also shown to be (marginally) negatively related to fear of failure when tested alone, but not with SDE controlled. Thus, the link between IM and each of the approach motives appears to have a substantive basis, but the data are inconclusive regarding the link between IM and the avoidance motive.

\section{Studies 2a and 2b}

In Studies 2a and 2b we investigated relations between IM and achievement goals, namely, the goals of the 2 x 2 achievement goal model. In Study 2 a we investigated these relations only, whereas in Study $2 \mathrm{~b}$ we also examined SDE-achievement goal relations and the IM-achievement goal relations with SDE controlled. Study 2a was conducted with undergraduates in Saudi Arabia, whereas Study 2b was conducted with undergraduates in the U.S. This allowed us to examine the presence of absence of cultural differences in the focal relations.

\section{Study 2a}

\section{Method}

\section{Participants and Procedure}

539 female undergraduates in psychology classes in Saudi Arabia participated for extra course credit. Male participants were not acquired in this study, because it is extremely difficult to recruit an adequate sampling of males in this cultural context. We had no sex-related hypotheses in the research, nor any clear reason to expect sex differences, hence we did not consider this an impediment to the work (ancillary analyses support this conclusion - see Footnote 3 ). The mean age of participants was 22.50 years old (range $=18-47)$, and participant 
ethnicity was exclusively Saudi. All questionnaires were translated from English to Arabic (including back translation processes). Participants completed the IM questionnaire online during the first month of the semester, and completed the achievement goal measure online during the second month of the semester.

\section{Measures}

Achievement goals. Elliot and Murayama's (2008) Achievement Goal QuestionnaireRevised (AGQ-R) was used to assess participants' 2 × 2 achievement goals for their classes (3 items per goal: Mastery-approach (e.g., "My goal is to learn as much as possible;" $\alpha=.78$ ), mastery-avoidance (e.g., "My goal is to avoid learning less than it is possible to learn"; $\alpha=$ .72), performance-approach (e.g., "My goal is to perform better than the other students"; $\alpha=$ .80), and performance-avoidance (e.g., "My goal is to avoid performing poorly compared to others"; $\alpha=.82$ ). Participants responded on a 1 (not at all true for me) to 5 (extremely true for me) scale. ${ }^{2}$

IM. The BIDR (Paulhus, 1991) was used to assess IM $(\alpha=.72)$; SDE was not assessed. Participants responded on a 1 (not at all true of me) to 5 (extremely true of me) scale.

\section{Results and Discussion}

We computed Pearson Product Moment Correlations to examine the relations between IM and each of the achievement goals (see Table 2). The correlations revealed statistically significant positive relations between IM and both mastery-approach goals $(r=.21, p<.001)$ and mastery-avoidance goals $(r=.19, p<.001)$; no statistically significant relation was observed for the performance-based goals. In this study, SDE was not assessed and so could not be controlled; we attended to this limitation in Study 2b. 
Table 2

Impression management and achievement goals (Studies 2a / 2b).

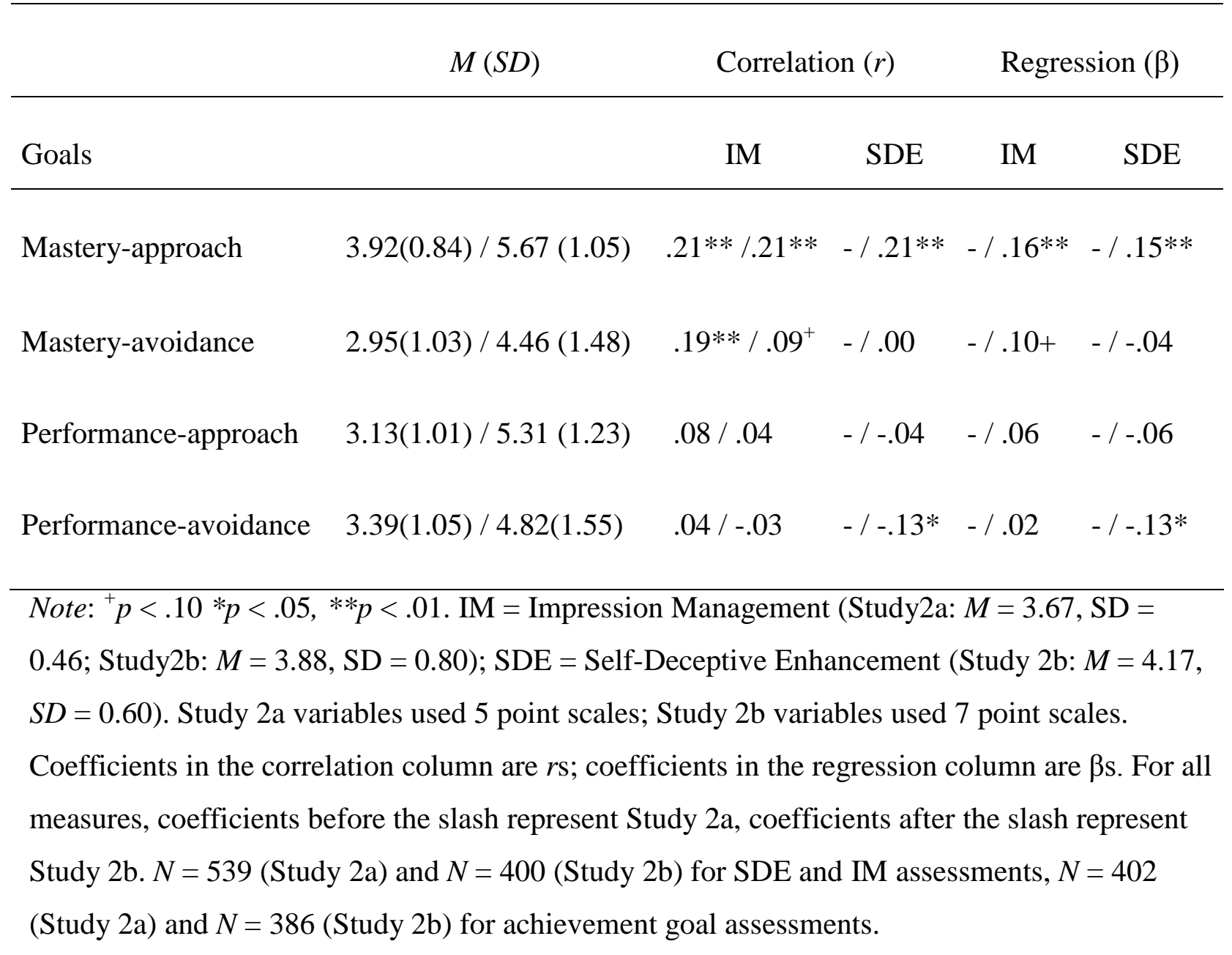

All but one of the aforementioned relations (the IM-fear of failure link), remained statistically significant when SDE was controlled. This suggests that IM scores carry substantive 
variation, consistent with Uziel's (2010) analysis. Achievement motives and goals may thus be added to the growing list of constructs to which IM appears to be systematically and substantively connected (see also Uziel, 2013).

\section{Study 2b}

Method

\section{Participants and Procedure}

400 undergraduates (65.0\% female) in a psychology class in the U.S. participated for extra course credit. The mean age of participants was 19.4 years old (range $=17-32$ ), and participant ethnicity: 56.3\% Caucasian, 6.5\% African-American, 24.8\% Asian, 5.0\% Hispanic, 7.4\% “Other/unspecified". Participants completed the IM and SDE questionnaires online during the first week of the semester, and completed the achievement goal measure online approximately two weeks later.

\section{Measures}

Achievement goals. The AGQ-R was used to assess participants' 2 × 2 achievement goals for their class (mastery-approach $\alpha=.87$, mastery-avoidance $\alpha=.78$, performanceapproach $\alpha=.86$, performance-avoidance $\alpha=.89$ ). Participants responded on a 1 (not true of me) to 7 (extremely true of me) scale.

$I M$ and SDE. The BIDR was used to assess IM $(\alpha=.78)$ and $\operatorname{SDE}(\alpha=.70)$. Participants responded on a 1 (Not True) to 7 (Very True) scale.

\section{Results and Discussion}

We computed Pearson Product Moment Correlations to examine the relations between IM, SDE, and each of the achievement goals (see Table 2). The correlations revealed a statistically significant positive relation between IM and mastery-approach goals $(r=.21, p<$ 
$.001)$ and a marginally significant positive relation between IM and mastery-avoidance goals ( $r=$ $.09, p=.070$ ); no statistically significant relation was observed for the performance-based goals. ${ }^{3}$ The correlations also revealed a statistically significant positive relation between SDE and mastery-approach goals $(r=.21, p<.001)$ and a statistically significant negative relation between SDE and performance-avoidance goals $(r=-.13, p=.012)$.

We conducted multiple regression analyses to examine IM and SDE as simultaneous predictors of each of the achievement goals. IM was shown to be a statistically significant positive predictor of mastery-approach goals $(\beta=.16, p=.002)$, as was $\operatorname{SDE}(\beta=.15, p=.003)$. IM was a statistically significant positive predictor of mastery-avoidance goals $(\beta=.10, p=$ .054) and SDE was a statistically significant negative predictor of performance-avoidance goals $(\beta=-.13, p=.013)$. No statistically significant results were obtained with performance-approach goals.

In sum, IM was shown to be positively related to mastery-approach and masteryavoidance goals, but no statistically significant relations emerged between IM and both performance-approach and performance-avoidance goals. This was the case when these links were tested alone and when tested with SDE controlled, suggesting that the IM-mastery goal links have a clear, substantive basis. The results were consistent across Studies $2 \mathrm{a}$ and $2 \mathrm{~b}$, despite these investigations being conducted in very different cultural contexts -- Saudi Arabia and the U.S., respectively.

\section{General Discussion}

Prior research on the IM-achievement motivation relation has only focused on omnibus achievement motivation, namely the need for achievement; null findings have been observed. In the present research, we focused on differentiated achievement motivation constructs and 
observed several systematic IM-achievement motivation links. Specifically, IM was a positive predictor of the workmastery motive, mastery-approach goals, and mastery-avoidance goals, and was a negative predictor of the competitiveness and fear of failure motives. This highlights the importance of considering the motive/goal, self/other, and approach/avoidance distinctions in studying achievement motivation.

Our research not only highlights the importance of viewing IM as a personality variables in its own right and extends the IM nomological network, but also sheds light on the nature of the achievement motive and achievement goal constructs. Our findings suggest that individuals high in self-control for the purpose of social adaption (IM) orient their competence-relevant desires toward intrapersonal success (workmastery) rather than interpersonal success (competitiveness). Likewise, these individuals focus their competence-relevant pursuits on approaching intrapersonal success (mastery-approach goals) and avoiding intrapersonal failure (mastery-avoidance goals). Each of these links may be construed as self-regulation aimed at acquiring outcomes in achievement settings in a way that is sensitive to both widely endorsed values and the feelings of others. Research to date in the achievement motivation literature has emphasized the negative implications of commingling achievement and affiliation concerns. For example, concern about losing the love of important others has been linked to fear of failure and performance-avoidance goal pursuit (Elliot \& Thrash, 2004), and a focus on demonstrating ability to others has been linked to self-protection and low levels of persistence (Dweck \& Leggett, 1986; Nicholls, 1989). The present findings are enlightening, in that they point to a positive implication of this achievement-affiliation comingling -- attending to social values and the feelings of others can facilitate motivation known to be beneficial for a number of achievement-relevant processes and outcomes (e.g., high effort expenditure, optimal study 
strategies, intrinsic interest; Hulleman, Schrager, Bodmann, \& Harackiewicz, 2010; Meece, Anderman, \& Anderman, 2006).

In our studies, SDE was positively related to workmastery and mastery-approach goals, and was negatively related to fear of failure and performance-avoidance goals. These relations are consistent with Paulhus' (1991) portrait of SDE as a (nonconscious) tendency to see oneself in an overly positive light. Workmastery and mastery-approach goals are clearly desirable forms of motivation (pure approach) and fear of failure and performance-avoidance goals are clearly undesirable forms of motivation (pure avoidance; Darnon et al., 2009; Elliot, 1999), and those high in SDE reported higher values for the former set of variables and lower values for the latter. Moreover, when controlling for SDE, the positive relations between IM and both workmastery and mastery-approach goals were reduced to some degree (although they remained statistically significant), and the marginally significant negative relation between IM and fear of failure was no longer even marginal when SDE was controlled. To the extent that SDE captures social desirability variation (see Uziel, 2014), these findings suggest that IM scores are not completely devoid of social desirability, but instead represent a combination of substantive and extraneous variance. Future work would do well to seek to systematically isolate these sources of variance, and to test implications therein for IM as a predictor variable (for an elegant prototype of such work, see Dompnier et al., 2009).

Future research is also needed to further explore some questions raised by the findings of our research. One such question is why IM was not substantively related to fear of failure, as we had predicted; the weak and nonsignificant relations observed herein must be considered inconclusive, awaiting a more powerful test. Another question is why IM was a statistically significant negative predictor of approaching other-based competence at the motive level 
(competitiveness), but not at the goal level (performance-approach goals). In addition, research is needed to examine IM-achievement motivation links using other IM measures, beside the one from the BIDR used herein. Finally, it remains possible that individuals high in IM faked having competence-relevant desires/foci toward intrapersonal processes rather than truly having such desires/foci; subsequent work incorporating external, objective (i.e., non-self-report) criteria would be welcomed to test this possibility (Dompnier et al., 2009).

In closing, the present research highlights the value of conceptualizing and utilizing IM as a substantive variable. Linking IM to the achievement motivation domain yielded interesting insights into the nature of differentiated achievement motive and goal constructs, and we think IM holds similar promise for research in other domains of inquiry as well. 


\section{Footnotes}

1. In reviewing this literature, we focus on studies explicitly designed to examine correlates of IM.

2. The achievement goals items were those from the AGQ-R, but a new set of instructions and formatting was used (available from the lead author upon request) to maximize participant understanding and attention.

3. Study 2a, which examined IM-achievement goal relations, only included females, so in Study $2 \mathrm{~b}$ we also tested whether sex interacted with IM in predicting the achievement goal variables. Neither of the central findings for mastery-based goals were moderated by sex; a Sex x IM interaction was observed for performance-approach goals $(t=2.15, p=0.032)$, but examining the IM-achievement goal relation for each sex revealed that the link was not statistically significant for either. 


\section{Acknowledgements}

This project was funded by the Deanship of Scientific Research (DSR), King Abdulaziz

University, Jeddah, under grant no. /1432/HiCi. The authors, therefore, acknowledge with thanks DSR technical and financial support. 


\section{References}

Ames, C. (1992). Classrooms: Goals, structures, and student motivation. Journal of Educational Psychology, 84, 261-271.

Atkinson, J. W. (1957). Motivational determinants of risk taking behavior. Psychological Review, 64, 359-372.

Crowne, D. P. (1979). The experimental study of personality. Hillsdale, NJ: Erlbaum.

Crowne, D. P., \& Marlowe, D. A. (1964). The approval motive: Studies in evaluative dependence. NY: Wiley.

Darnon, C., Dompnier, B., Delmas, F., Pulfrey, C., \& Butera, F. (2009). Achievement goals promotion at university: Social desirability and social utility of mastery and performance goals. Journal of Personality and Social Psychology, 96, 119-134.

Deutsch, M. (1949). A theory of cooperation and competition. Human Relations, 2, 129-152.

Dompnier, B., Darnon, C., \& Butera, F. (2009). Faking the desire to learn: A clarification of the link between mastery goals and academic achievement. Psychological Science, 20, 939943.

Dweck, C. S., \& Elliott, E. S (1983). Achievement motivation. In P. Mussen (Series Ed.) \& E. Hetherington (Vol. Ed.), Handbook of child psychology: Vol. 4. Socialization, personality and social development (4th ed., pp. 643-691). New York: Wiley.

Dweck, C. S., \& Leggett, E. L. (1988). A social-cognitive approach to motivation and personality. Psychological Review, 95, 256-273.

Elliot, A. J. (1999). Approach and avoidance motivation and achievement goals. Educational Psychologist, 34, 169-189.

Elliot, A. J., \& Murayama, K. (2008). On the measurement of achievement goals: Critique, 
illustration, and application. Journal of Educational Psychology, 100, 613-628.

Elliot, A. J., \& Reis, H. T. (2003). Attachment and exploration in adulthood. Journal of Personality and Social Psychology, 85, 317-331.

Elliot, A. J., \& Thrash, T. M. (2002). Approach-avoidance motivation in personality: Approach and avoidance temperaments and goals. Journal of Personality and Social Psychology, 82, 804-818.

Elliot, A. J., \& Thrash, T. M. (2004). The intergenerational transmission of fear of failure. Personality and Social Psychology Bulletin, 30, 957-971.

Holden, R. R., Fekken, G. C. (1989). Three common social desirability scales: Friends, acquaintances, or strangers? Journal of Research in Personality, 23, 180-191.

Hulleman, C. S., Schrager, S. M., Bodmann, S. M., \& Harackiewiciz, J. M. (2010). A metaanalytic review of achievement goal measures: Different labels for the same constructs or different constructs with similar labels? Psychological Bulletin, 136, 422-449.

Meece, J. L., Anderman, E. M., \& Anderman, L. H. (2006). Classroom goal structure, student motivation, and academic achievement. Annual Review of Psychology, 57, 487-503.

Moorman, R. H., \& Podsakoff, P. M. (1992). A meta-analytic review and empirical test of the potential confounding effects of social desirability response sets in organizational behavior research. Journal of Occupational and Organizational Psychology, 65, 131-149.

Nicholls, J. G. (1989). The competitive ethos and democratic education. Cambridge, MA: Harvard University Press.

Paulhus, D. L. (1991). Measurement and control of response bias. In J. Robinson \& P. Shaver (Eds)., Measurement of personality and social psychological attitudes (Vol. 1, pp. 1759). San Diego, CA: Academic Press. 
Paulhus, D. L. (2002). Social desirable responding: the evolution of a construct. In H. Braun, D. Jackson, \& D. Wiley (Eds.), The role of constructs in psychological and educational measurement (pp. 67-88). Hillsdale, NJ: Erlabaum.

Pauls, C. A., Wacker, J., \& Crost, N. W. (2005). The two components of social desirability and their relations to resting frontal brain asymmetry. Journal of Individual Differences, $26,29-42$.

Schlenker, B. R., \& Britt, T. W. (2001). Strategically controlling information to help friends: Effects of empathy and friendship strength on beneficial impression management. Journal of Experimental Social Psychology, 37, 357-372.

Spence, J., \& Helmreich, R. (1983). Achievement-related motives and behaviors. In J. Spence (Ed.), Achievement and achievement motives: Psychological and sociological approaches (pp. 10-74). San Francisco: N. H. Freeman.

Strickland, B. R. (1977). Approval motivation. In T. Blass (Ed.), Personality variables in social behavior (pp. 315-366). Hillsdale, NJ: Erlbaum.

Tangney, J. P., Baumeister, R. F., \& Boone, A. L. (2004). High self-control predicts good adjustment, less pathology, better grades, and interpersonal success. Journal of Personality, 72, 271-322.

Thrash, T. M., \& Elliot, A. J. (2003). Inspiration as a psychological construct. Journal of Personality and Social Psychology, 84, 871-889.

Uziel, L. (2014). Impression management ("lie") scales are associated with interpersonally oriented self-control, not other deception. Journal of Personality, 82, 200-212.

Uziel, L. (2010). Rethinking social desirability scales: From impression management to interpersonally oriented self-control. Perspectives on Psychological Science, 5, 243-262. 
Weidman, A. C., Tracy, J. L., \& Elliot, A. J. (in press). The benefits of following your pride: Authentic pride promotes achievement. Journal of Personality. 